\title{
Novel Zero-Voltage-Switching Bridgeless PFC Converter
}

\author{
Rasool Haghi ${ }^{\dagger}$, Mohammad Reza Zolghadri* , and Reza Beiranvand ${ }^{* *}$ \\ $\dagger^{* *}$ Department of Electrical Engineering, Sharif University of Technology, Tehran, Iran \\ ** Department of Electrical and Computer Engineering, Tarbiat Modares University, Tehran, Iran
}

\begin{abstract}
In this paper, a new zero-voltage-switching, high power-factor, bridgeless rectifier is introduced. In this topology, an auxiliary circuit provides soft switching for all of the power semiconductor devices. Thus the switching losses are reduced and the highest efficiency can be achieved. The proposed converter has been analyzed and a design procedure has been introduced. The control circuit for the converter has also been developed. Based on the given approach, a $250 \mathrm{~W}, 400 \mathrm{Vdc}$ prototype converters has been designed at $100 \mathrm{kHz}$ for universal input voltage (90-264 Vrms) applications. A maximum efficiency of $94.6 \%$ and a power factor correction over 0.99 has been achieved. The simulation and experimental results confirm the design procedure and highlight the advantages of the proposed topology.
\end{abstract}

Key words: Bridgeless PFC, Power-factor-correction (PFC), Soft switching; Zero-voltage-switching (ZVS)

\section{NOMENCLATURE}

$V_{C_{r}}(t) \quad$ : Voltage across $\mathrm{C}_{\mathrm{r}}$.

$M_{C_{r}}(t) \quad$ : Normalized voltage across capacitor $\mathrm{C}_{\mathrm{r}}$.

$I_{L r}(t) \quad$ : Current of $\mathrm{L}_{\mathrm{r}}$.

$J_{L_{r}}(t) \quad$ : Normalized current of $\mathrm{L}_{\mathrm{r}}$.

$J_{\text {in }} \quad$ : Normalized input current.

$T_{s} \quad$ : Switching period.

$f_{S} \quad:$ Switching frequency.

$T_{f} \quad:$ Fall time

$I_{S_{-} \text {peak }} \quad$ : Main switches peak current.

$V_{o} \quad$ : Output Voltage.

$V_{\text {in }} \quad$ : Input voltage.

$C_{r} \quad:$ Represent ${ }^{\text {' }} \mathrm{C}_{\mathrm{r} 1}$ ' or ' ' $\mathrm{C}_{\mathrm{r} 2}$ '

$L_{r} \quad$ : Represent ' $\mathrm{L}_{\mathrm{r} 1}$ ' or ' $\mathrm{L}_{\mathrm{r} 2}$ '

$K_{r} \quad$ : Normalized L current ripple d $\left(\Delta i_{l} / I_{l}\right)$

$t_{r r} \quad:$ Rated reverse recovery time for Diodes

Manuscript received May 5, 2012; revised Nov. 9, 2012

Recommended for publication by Associate Editor Bor-Ren Lin.

†Corresponding Author: haghirasool@gmail.com

Tel: +98-913-272-6018, Sharif University of Technology

*Department of Electrical Engineering, Sharif University of Technology,

Iran

${ }^{* *}$ Department of Electrical and Computer Engineering, Tarbiat Modares University, Tehran, Iran

\section{INTRODUCTION}

To overcome the challenges of the ever-increasing power densities of today's ac/dc power supplies, designers are continuously looking for opportunities to maximize efficiency, minimize the components count, and reduce the size of components. Conventional rectifiers encounter excessive peak input current and total harmonic distortion (THD) which reduce the power factor (PF) to about 0.5-0.7 [1]. Power factor correction (PFC) converters are employed to decrease these harmonics. A conventional type of PFC converter, which is usually controlled by the average current pulse width modulation (PWM) method, is a full-bridge rectifier followed by a boost converter, as shown in Fig. 1(a) [2]-[4]. However, it suffers from low efficiency and high stress on the main switch. Increasing the switching frequency reduces the volume and weight of the converter but, leads to higher switching losses. Therefore, using the soft-switching techniques is unavoidable for high switching frequency applications. Zero voltage switching (ZVS) and zero-current switching (ZCS) are soft-switching techniques which provide soft switching while retaining the desirable features of conventional PWM converters. ZVS techniques eliminate the turn-on capacitive losses. Thus MOSFETs are preferred for ZVS techniques [2]. The turn-off switching losses caused by tail currents, are a major part of the total switching losses in IGBTs. Therefore, in these converters, using ZCS techniques is more efficient than 
ZVS techniques. In some PFC rectifiers, due to high input voltage variations ( 0 to peak value of the input ac voltage), ZVS may be realized in a restricted area in a utility line cycle. This limits the input ac voltage. Moreover, in conventional boost based PFC converters, conduction losses are higher when compared to diode rectifiers [7], [8]. To reduce conduction losses, the rectifier circuit and the PFC have been combined to introduce a bridgeless PFC converter, as shown in Fig. 1(b) [1], [6]. This combination decreases the conduction losses by reducing the number of semiconductor components in the line current path [9]-[13]. In bridgeless PFC, the body diode of $\mathrm{S}_{2}$ conducts in the entire positive half line cycle and the body diode of $S_{1}$ conducts in the entire negative half line cycle. Using the ZVS technique for this converter can lead to even higher efficiencies. In this paper, a new ZVS PFC converter is proposed. The proposed converter consists of an auxiliary circuit which can provide the ZVS condition for the main switches if it is controlled properly. Conventional ZVS topologies reduce the turn-on switching losses, but the proposed topology reduces the overlap between the voltage and the current on the power switches both during switch turn-off and turn-on (section IV). Therefore, bridgeless PFC and the ZVS technique reduce conduction losses and switching losses, respectively. This maximizes the efficiency and consequently the limitation on switching frequency can be eliminated.

The converter operation and design procedure based on the steady-state are analyzed in the next section. The elimination of the turn-off switching losses is explained in Section IV. In section $\mathrm{V}$ the current control strategy is introduced. The design procedure is discussed in Section VI. The simulation and experimental results from a $250 \mathrm{~W}, 400 \mathrm{Vdc}$ prototype converter at $100 \mathrm{kHz}$ for universal input voltage (90-264 Vrms) applications are given in Section VII and VIII, respectively. These results verify the feasibility of the design process and the advantages of the proposed topology. The proposed converter is suitable for single-phase, power factor correction and universal input voltage applications where high efficiency and low EMI (Electro Magnetic Interference) are important.

\section{THE NOVEL TOPOLOGY AND ITS OPERATION}

Fig. 2 shows the proposed single-phase bridgeless ZVS-PFC converter. The denoted circuit in the dotted box is the proposed auxiliary circuit which provides soft switching for the main switches. $\mathrm{C}_{\mathrm{s} 1}$ and $\mathrm{C}_{\mathrm{s} 2}$ shown across $\mathrm{S}_{1}$ and $\mathrm{S}_{2}$ are the parasitic capacitance of the switches.

$\mathrm{L}_{\mathrm{r} 1}$ and $\mathrm{L}_{\mathrm{r} 2}$ provide soft switching for the main diodes $\left(\mathrm{D}_{1}\right.$, $\mathrm{D}_{2}$ ) and reduce di/dt at turn-off times. To provide soft switching for the main power switches at turn-on, the auxiliary switch is turned on for a fixed period of time. This provides the soft switching condition for the main switches and reduces the overlap between the current and the voltage at switching times.

The bridgeless PFC operation is symmetrical in the two

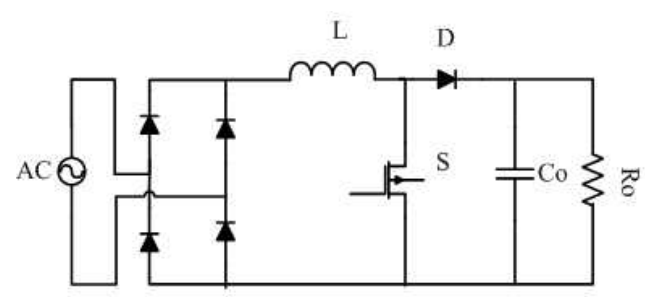

(a)

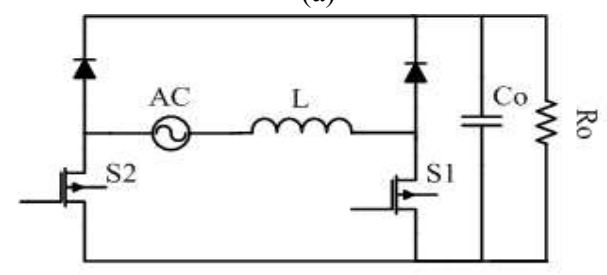

(b)

Fig. 1. (a) Conventional boost PFC converter. (b) Conventional bridgeless PFC converter.

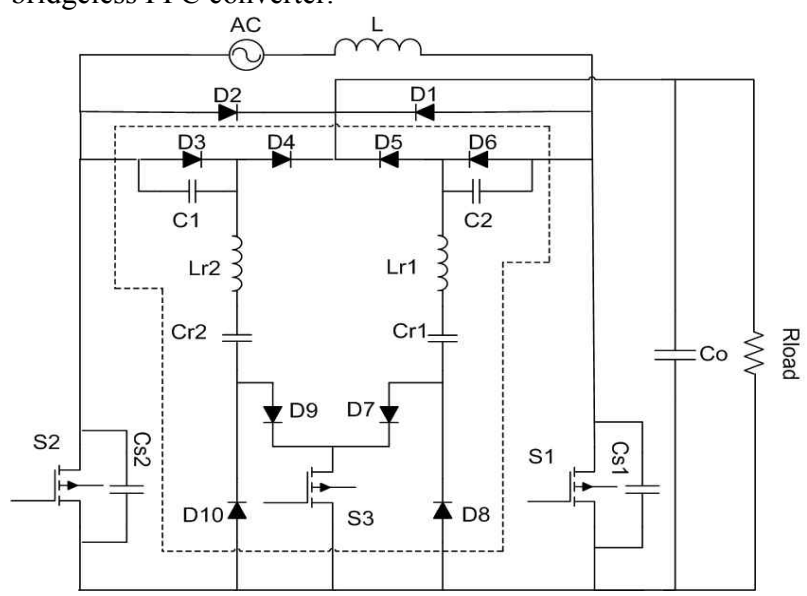

Fig. 2. Proposed ZVS bridgeless PFC converter topology

input line half-cycles. Therefore, one half-cycle of the converter operation is explained here. The auxiliary circuit is divided into two symmetric sections too. Due to the input line half-cycles, one section is inactive. Thus another section of the proposed auxiliary circuit provides the soft switching condition for the main switches. Thus both sections have no effect on the converter efficiency when they are in the inactive mode.

During the subinterval where the converter behaves like a PWM boost converter in the charging and transferring modes, all of the auxiliary components are inactive. Therefore, there is no additional loss in these states.

In order to explain the operation of the converter and to quantify its behavior, the following conditions are assumed:

All components are ideal; the converter operates in the steady state at a fixed switching frequency $\left(\mathrm{f}_{\mathrm{s}}\right)$. The input voltage $\left(\mathrm{V}_{\text {in }}\right)$ is a sine wave that is assumed to be constant $\left(\mathrm{V}_{\mathrm{g}}\right)$ in a switching cycle. The output voltage $\left(\mathrm{V}_{\mathrm{o}}\right)$ is also constant, and the switching frequency is much higher than the ac line frequency. In addition, the input inductor $(\mathrm{L})$ is large enough to be replaced by a current source $\left(\mathrm{I}_{\text {in }}\right)$ during the converter switching period $\left(\mathrm{T}_{\mathrm{s}}\right)$. 
The operation of the converter in a half cycle of the utility line voltage can be divided in 8 subintervals. The equivalent circuits at each subinterval and the theoretical waveforms have been illustrated in Fig. 3 and 4, respectively.

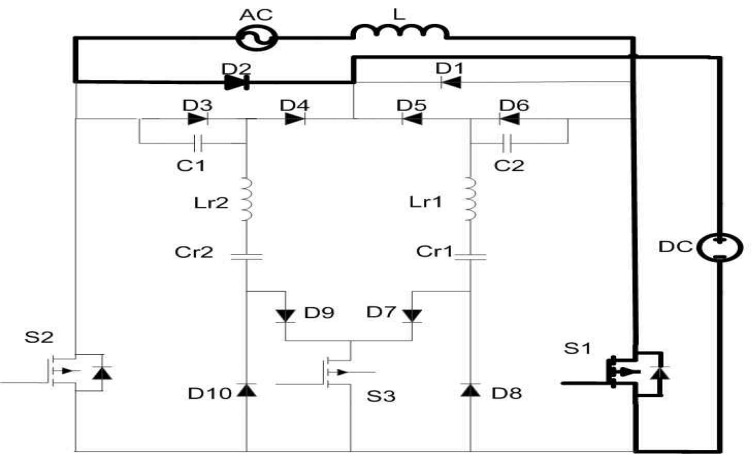

(a)

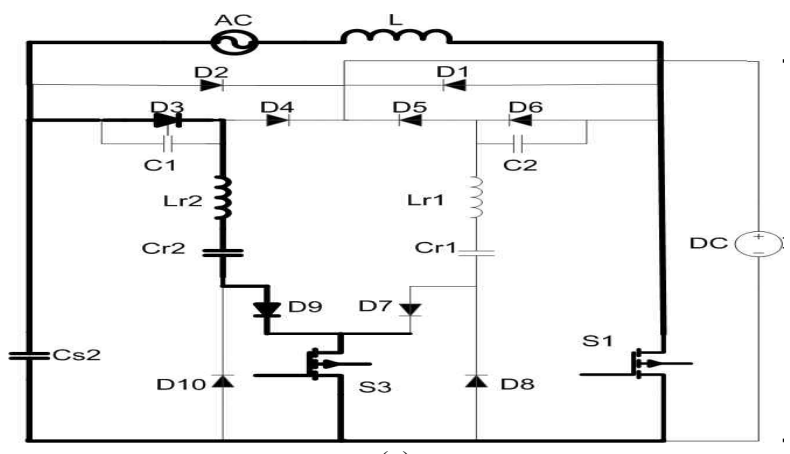

(c)

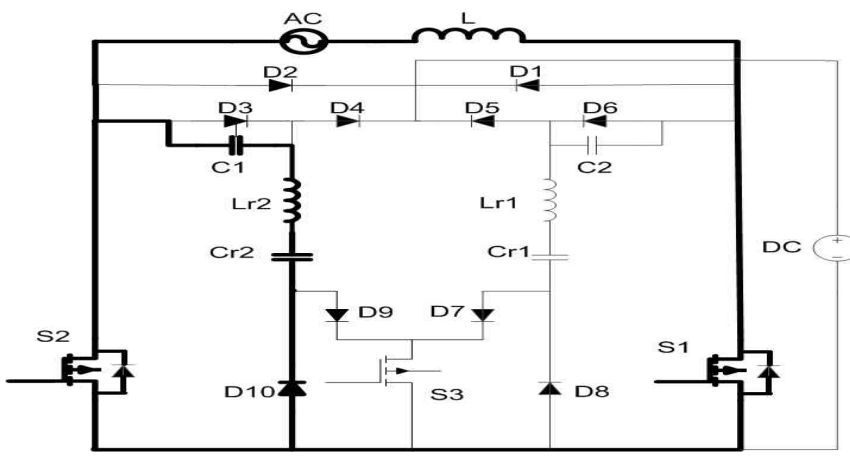

(e)

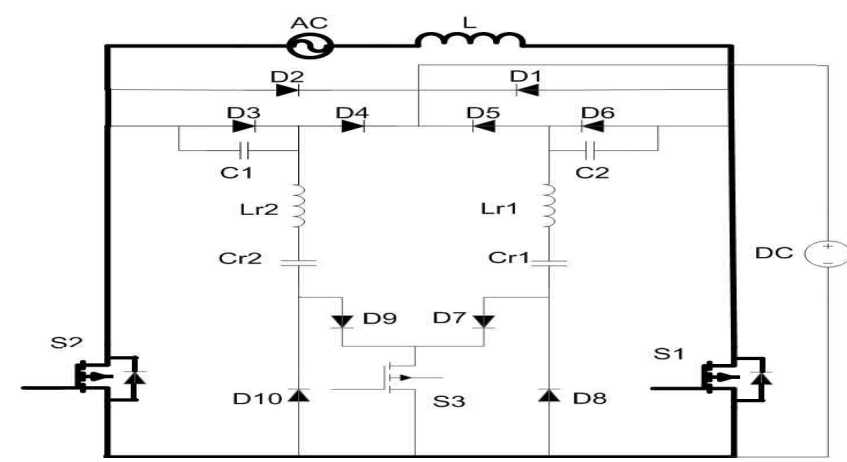

(g)

\section{A. Subinterval 1 [t0-t1] [Fig. 3(a)]}

This subinterval is considered just to show the initial condition of the switching operation. During this subinterval, $\mathrm{D}_{2}$ (the boost diode) and the body diode of $\mathrm{S}_{1}$ are conducting. The load current and the converter are behaving as a simple

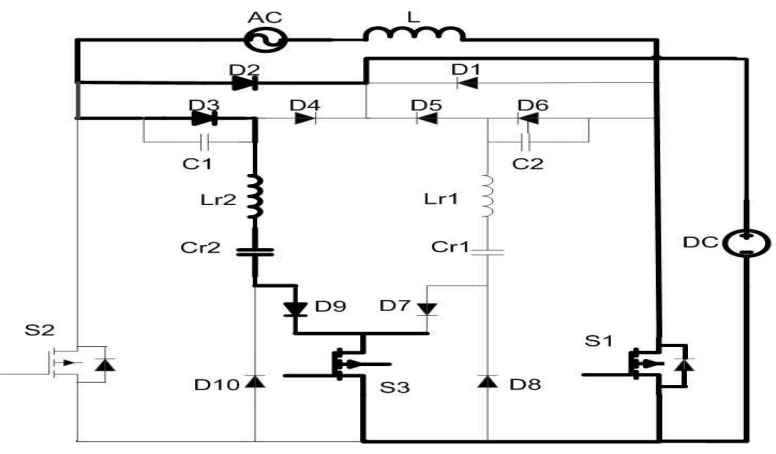

(b)

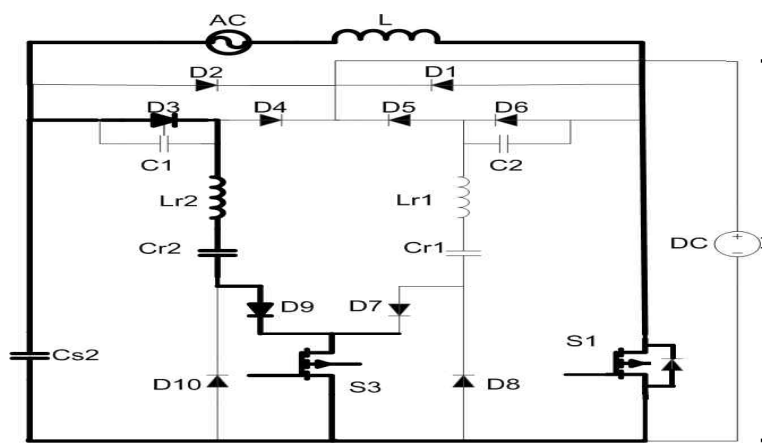

(d)

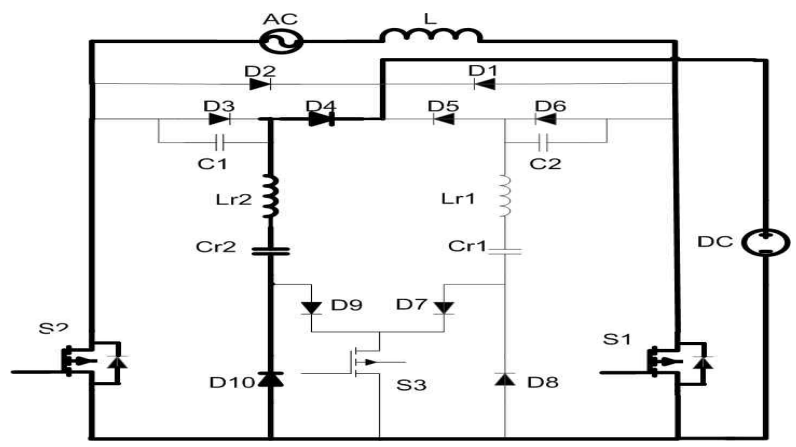

(f)

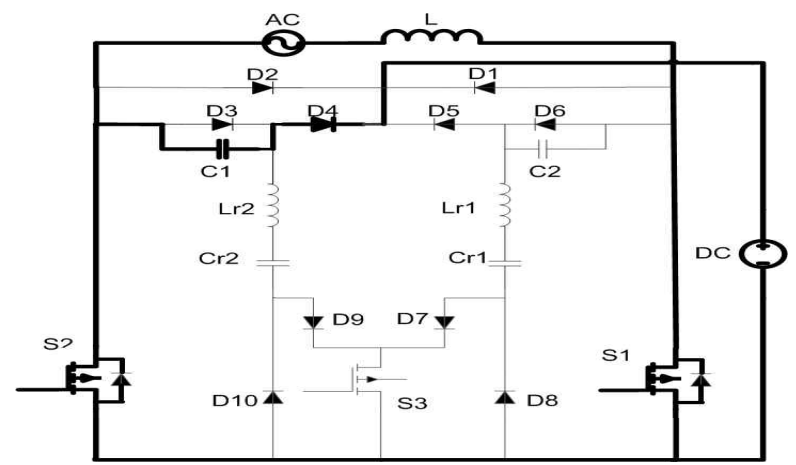

(h)

Fig. 3. The main current flow paths in the converter during a switching period (a) Subinterval 1. (b) Subinterval 2. (c) Subinterval 3. (d) Subinterval 4. (e) Subinterval 5. (f) Subinterval 6. (g) Subinterval 7. (h) Subinterval 8. 
PWM boost converter where its switch is off and the diode is on. This subinterval is finished when the PFC controller turns on $\mathrm{S}_{3}$ to start the resonance in the auxiliary circuit before turning the main switch $\left(\mathrm{S}_{2}\right)$ on.

\section{B. Subinterval $2\left[t_{1}-t_{2}\right]$ [Fig.3(b)]}

This subinterval begins by turning $\mathrm{S}_{3}$ on and ends when the current of $D_{2}$ reaches zero. Due to $L_{r 2}$, this switch turns on with the zero current $(\mathrm{ZC})$ condition. $\mathrm{L}_{\mathrm{r} 2}$ also slows down the turn-off di/dt through the boost diode $\mathrm{D}_{2}$. The current slowly starts diverting from $\mathrm{D}_{2}$ to the auxiliary resonant circuit (consisting of $\mathrm{L}_{\mathrm{r} 2}$ and $\mathrm{C}_{\mathrm{r} 2}$ ). Therefore, $\mathrm{D}_{2}$ is turned-off at the zero current at instant $t_{2}$. Consider the converter equivalent circuit, as shown in Fig.3 (b). The state plane trajectory is given in Fig. 5. Solving the state plane geometry, the following is obtained:

$$
\alpha=\cos ^{-1}\left(M-M_{C r 2}\left(t_{2}\right) / M-M_{C r 2}\left(t_{1}\right)\right)
$$

where:

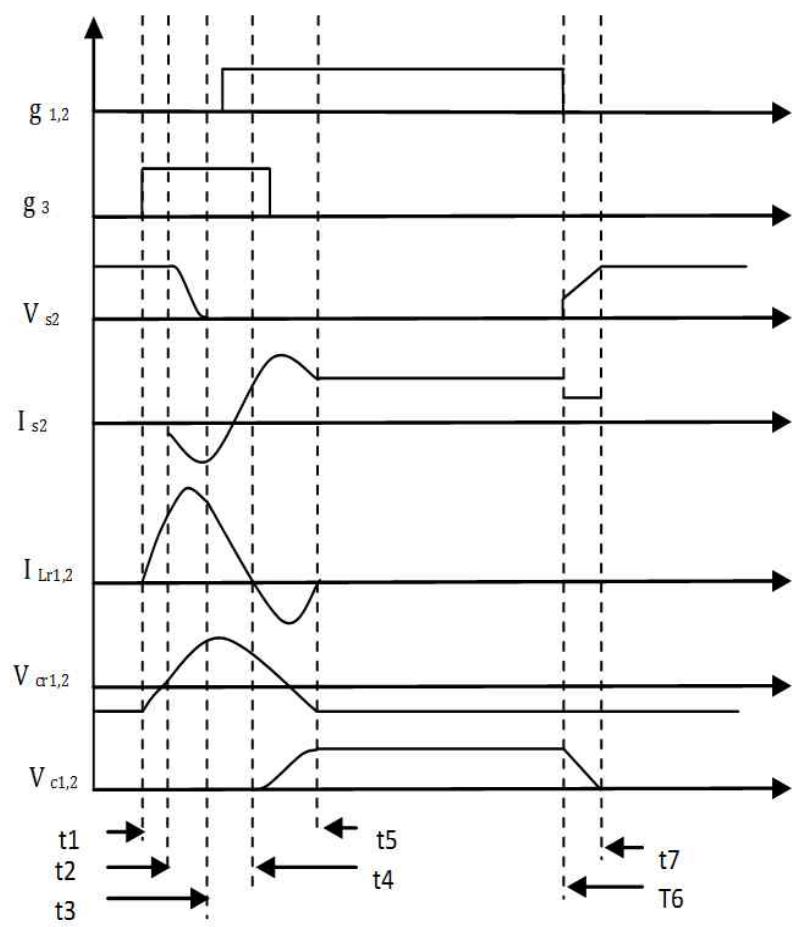

Fig. 4. Theoretical auxiliary circuit's waveforms during a switching period.

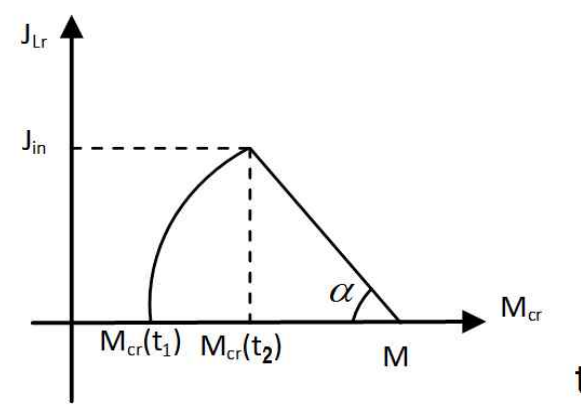

Fig. 5. State plane trajectory of subinterval 2.
$I_{L r 2}\left(t_{1}\right)=0, M_{C r 2}\left(t_{2}\right)=M-J_{i n} \cot g(\alpha), t_{2}=\alpha / \omega_{2}$, $V_{\text {base }}=V_{g}, R_{2}=R_{\text {base }}=\sqrt{L_{r 2} / C_{r 2}}, \omega_{2}=1 / \sqrt{L_{r 2} C_{r 2}}$

\section{Subinterval 3 [t2-t3] [Fig. 3(c)]}

This subinterval begins when the current through $D_{2}$ reaches zero and the current is passed through $\mathrm{C}_{\mathrm{s} 2}$. In this subinterval $S_{3}, D_{3}$ and $D_{9}$ are conducting. The equivalent circuit is a third order, as shown in Fig.3(c). The converter equivalent circuit's response can be considered as a resonant response (ringing, illustrated in Fig.6(a)) and as a non-resonant response (integrating ramp, illustrated in Fig.6(b)). Some of the parameters used in Fig.6, are calculated as follows:

$$
\begin{gathered}
\mathfrak{R}=C_{s 2} / C_{r 2}, C_{t}=\left(C_{s 2} C_{r 2}\right) /\left(C_{s 2}+C_{r 2}\right) \\
I_{t}=I_{\text {in }} /(1+\mathfrak{R}) \\
V_{\text {tot }}=V_{C r 2}-V_{C s 2} \\
V_{\Delta}=V_{C r 2}+\mathfrak{R} \times V_{C s 2}
\end{gathered}
$$

Where:

$$
\begin{aligned}
& V_{C s 2}=-V_{\text {tot }} /(1+\mathfrak{R})+V /(1+\mathfrak{R}) \\
& V_{C r 2}=(\mathfrak{R} /(1+\mathfrak{R})) \times V_{t o t}+V_{\Delta} /(1+\mathfrak{R}) \\
& R_{3}=R_{\text {base }}=\sqrt{L_{r 2}\left(C_{s 2}+C_{r 2}\right) / C_{r 2} C_{s 2}} \\
& \omega_{3}=1 / \sqrt{L_{r 2} \cdot\left(C_{s 2} C_{r 2} / C_{s 2}+C_{r 2}\right)}
\end{aligned}
$$

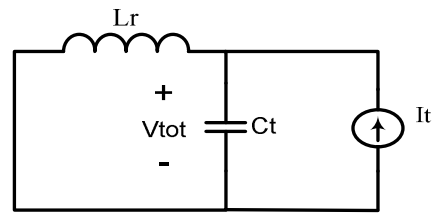

(a)

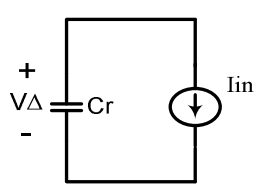

(b)
Fig. 6. Converter's simplified equivalent circuit in the $3 \mathrm{rd}$ Subinterval.(a) resonant part.(b) non-resonant part.

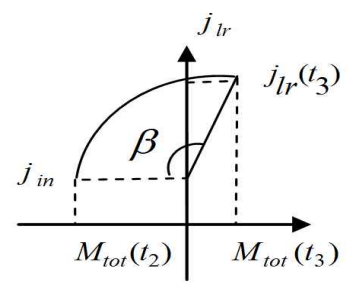

(a)

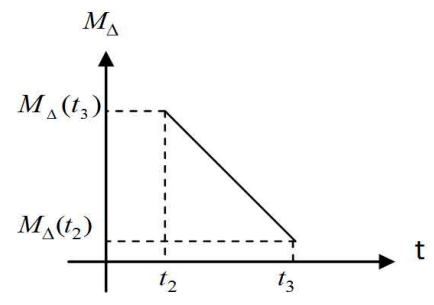

(b)

Fig 7. Converter's simplified equivalent circuit in the 3rd subinterval.(a) resonant part.(b) non-resonant part. 


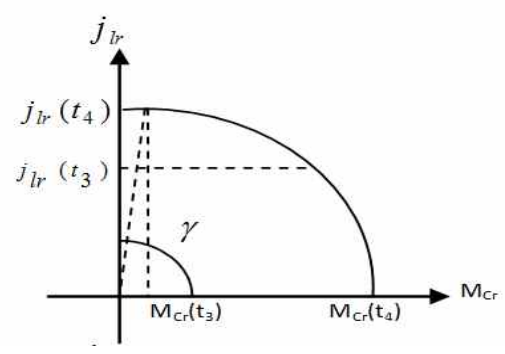

Fig. 8. State plane trajectory of Subinterval 4.

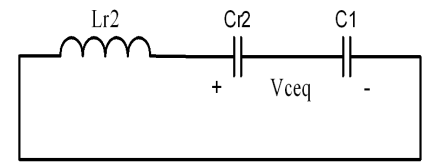

Fig. 9. Converter's equivalent circuit during Subinterval 5.

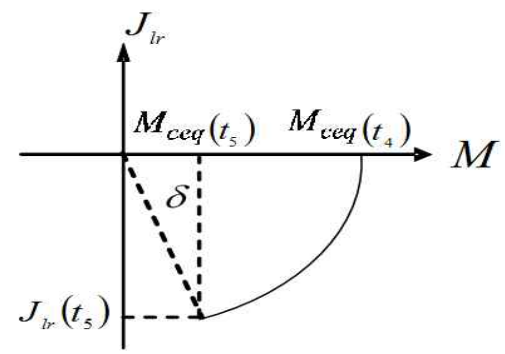

Fig. 10. State plane trajectory of Subinterval 5.

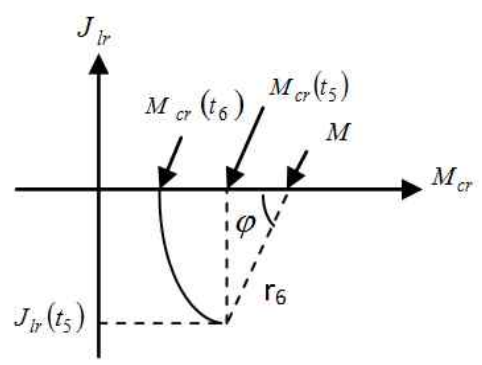

Fig. 11. State plane trajectory of Subinterval 6.

Subinterval 3 is finished when the $\mathrm{C}_{\mathrm{s} 2}$ voltage reaches zero, and the $\mathrm{S}_{3}$ current is reversed.

The resonant part state plane trajectory and the non-resonant state plane trajectory are shown in Fig. 7(a) and 7(b), respectively.

Considering the equivalent circuits, shown in Fig.3(c), Fig. 6 and Fig. 7 the following can be written:

$$
\begin{gathered}
J_{L r 2}\left(t_{3}\right)=M_{\text {tot }}\left(t_{2}\right) \times \sin (\pi-\beta)+J_{\text {in }} \\
\beta=\omega_{3} t_{3} \\
M_{C s 2}\left(t_{3}\right)=-(1 / 1+\mathfrak{R}) \times\left(M_{t o t}\left(t_{2}\right) \times \cos (\pi-\beta)\right) \\
+(1 / 1+\Re) \times\left(M_{\Delta}\left(t_{2}\right)-J_{\text {in }} \times \beta\right)=0 \\
M_{C r 2}\left(t_{3}\right)=(\mathfrak{R} / 1+\mathfrak{R}) \times\left(M_{t o t}\left(t_{2}\right) \times \cos (\pi-\beta)\right) \\
+(1 / 1+\mathfrak{R}) \times\left(M_{\Delta}\left(t_{2}\right)-J_{\text {in }} \times \beta\right.
\end{gathered}
$$

At the end of this subinterval the current through the resonant inductor $\mathrm{L}_{\mathrm{r} 2}$ is 0 , and voltage across the resonant capacitor $\mathrm{C}_{\mathrm{r} 2}$ is $\mathrm{Vc}_{\mathrm{r} 2}\left(\mathrm{t}_{3}\right)$. Based on the aforementioned equation, soft switching can be achieved when the following inequality is satisfied:

$$
J_{l r 2}\left(t_{3}\right)>J_{\text {in }}
$$

\section{Subinterval 4 [t3-t4] [Fig.3(d)]}

During this subinterval, $\mathrm{S}_{3}, \mathrm{D}_{3}, \mathrm{D}_{9}$ and the body diode of $\mathrm{S}_{2}$ are conducting. The current of $\mathrm{L}_{\mathrm{r} 2}$ decreases linearly until it reaches $I_{\text {in }}$ and the main switch $S_{2}$ is just about to start conduction. This is the ZVS subinterval where $S_{2}$ must be turned on. The current in the auxiliary circuit decreases below the input current through $\mathrm{L}$ and the difference between the two currents starts flowing through switch $\mathrm{S}_{2}$. This subinterval lasts till $t_{4}$ at which time the auxiliary circuit current becomes zero. The state plane trajectory is given in Fig.8.

From Fig.3(d) and Fig.8 the following expressions are derived:

$$
M_{C r 2}\left(t_{4}\right)=J_{L r 2}\left(t_{3}\right) / \sin \gamma
$$

where:

$$
\begin{aligned}
& \tan \gamma=J_{L r 2}\left(t_{2}\right) / M_{C r 2}\left(t_{2}\right), \omega_{4}=1 / \sqrt{L_{r 2} C_{r 2}} \\
& \gamma=\omega_{4} t_{4}, R_{4}=R_{\text {base }}=\sqrt{L_{r 2} / C_{r 2}}
\end{aligned}
$$

\section{E. Subinterval 5 [t4-t5] [Fig.3(e)]}

During this subinterval, $\mathrm{S}_{2}$ and $\mathrm{D}_{10}$ are on and the auxiliary circuit current reverses. Diode $\mathrm{D}_{9}$ prevents this current from flowing through $S_{3}$ and so the current is passed through $D_{10}$. This provides a ZVS turn-off condition for $\mathrm{S}_{3}$. The auxiliary switch $\mathrm{S}_{3}$ should be turned-off during this subinterval. At the same time, diode $\mathrm{D}_{3}$ diverts this current through capacitor $\mathrm{C}_{1}$ and charges it. Depending upon the amount of resonant current, this capacitor is charged to a voltage level equal to or lower than the output voltage. The equivalent circuit is shown in Fig.9. The state plane trajectory is given in Fig.10, where:

$$
V_{c e q}=V_{c_{r 2}}+V_{C 1}
$$

From Figs. 9 and 10 the following can be written:

$$
\begin{gathered}
J_{L r 2}\left(t_{5}\right)=M_{c e q}\left(t_{4}\right) \sin \delta \\
M_{C e q}\left(t_{5}\right)=M_{C 1}\left(t_{4}\right) \cos \delta \\
M_{c 1}\left(t_{5}\right)=M_{C e q}\left(t_{5}\right)-M_{C r 2}\left(t_{4}\right) \\
\delta=\omega_{5} t_{5}, \omega_{5}=\sqrt{1 / L_{r} C_{e q}}, C_{e q}=\left(C_{1} C_{r 2} / C_{1}+C_{r 2}\right)
\end{gathered}
$$

\section{F. Subinterval 6[t5-t6] [Fig.3(f)]}

During this subinterval D4, D10 and S2 are conducting. This subinterval ends at $t_{6}$ when the auxiliary circuit current reduces to zero. D4 and D10 are turned off at the $\mathrm{ZC}$ condition. The state plane trajectory is given in Fig.11. By solving the state plane geometry, the following is obtained:

$$
\left(r_{6}\right)^{2}=\left(J_{L r 2}\left(t_{5}\right)\right)^{2}+\left(M-M_{C r 2}\left(t_{5}\right)\right)^{2}
$$




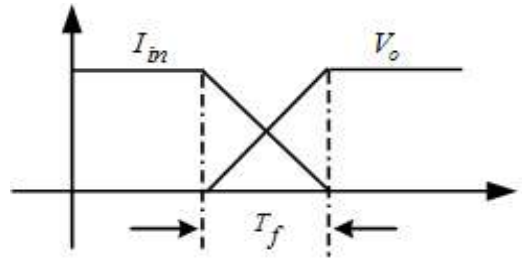

(a)

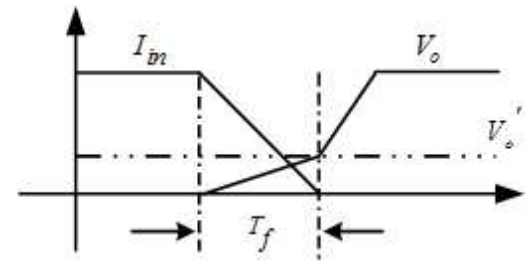

(b)

Fig. 12. Power MOSFET's current and voltage waveforms during the turned-off time (a) conventional converter, (b) proposed converter.

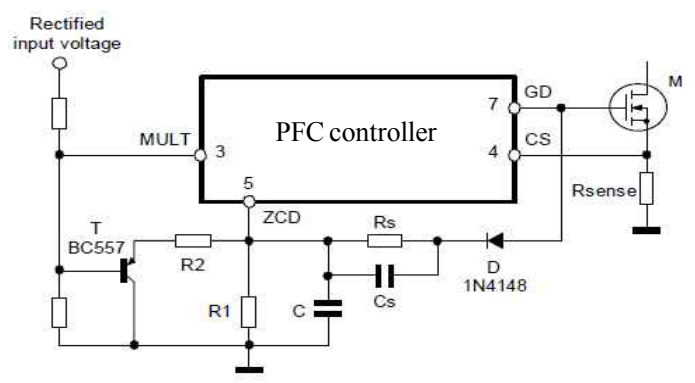

Fig. 13. Schematic of the employed Line-modulated Fixed-Off-Time PFC converter controller [17].

$$
\begin{aligned}
& \quad J_{L r 2}\left(t_{5}\right)=r_{6} \times \sin \varphi, M-r_{6}=M_{C r 2}\left(t_{6}\right), \varphi=\omega_{6} t_{6}, \\
& \omega_{6}=\sqrt{1 / L_{r 2} C_{r 2}}
\end{aligned}
$$

If $\mathrm{C}_{1}$ is charged to a value that is less than the output voltage, then D3 will not conduct. Later on, it will be clear that in such a case a reduced voltage will appear across S2 at the turn-off time instead of a zero voltage. D3 turns on if the following equation is satisfied:

$$
M_{C 1}\left(t_{6}\right)=M
$$

\section{G. Subinterval 7[t6-t7] [Fig.3(g)]}

In this subinterval $\mathrm{S}_{2}$ is conducting. The converter behaves like a PWM boost converter in the charging state and the auxiliary circuit is inactive. This subinterval ends when the main switch is turned-off.

\section{H. Subinterval 8[t7-t8] [Fig.3(h)]}

In this subinterval switch $\mathrm{S}_{2}$ is turned off at the ZVS conditions, and capacitor $\mathrm{C}_{\mathrm{s} 2}$ is charged until the voltage across it is equal to the output voltage. The capacitor $\mathrm{C}_{1}$ causes the voltage across $S_{2}$ to rise slowly because the net voltage appearing across $\mathrm{S}_{2}$ is the difference between the output voltage $V_{O}$ and the voltage across $C_{1}$. After $t_{8}$, the converter is in the same condition as in subinterval 1 , and another switching cycle will be started.

\section{REDUCING THE TURN-OFF OFF SWITCHING LOSSES}

As mentioned before, the ZVS techniques eliminates the turn-on switching losses. Fig.12(a) shows the current and voltage waveforms of a MOSFET during its turn-off time. Its turn-off switching losses can be estimated from Fig.12 (a) as follows:

$$
p_{\text {loss }}=\frac{1}{2} \cdot V_{o} \cdot I_{S_{1}-\text { peak }} \cdot F_{\text {sw }} \cdot\left(T_{f}\right)
$$

During subinterval 8 , when MOSFET $\mathrm{S}_{2}$ is turned off, its drain-source voltage increases very slowly until the stored energy in capacitor $\mathrm{C}_{1}$ is totally transferred to the output load. Therefore, when the current of the switch decreases to zero the drain-source voltage is much less than $\mathrm{V}_{\mathrm{O}}$. This can significantly reduce the turn-off switching losses. The current and the voltage of S2 in the proposed converter have been shown in Fig.12 (b).

In order to obtain good performance, the value of the capacitor $\mathrm{C}_{1}$ must satisfy (14).

In the proposed converter, the turn-on switching losses are approximately zero and the turn-off switching losses are reduced significantly. Although the proposed converter has 15 extra components, it reduces both the turn-off and the turn-on losses. Because of all of the auxiliary components operate for a tiny amount of time relative to the switching period time, they are low cost components. Moreover, bridgeless PFC is used which reduces the conduction losses and highest efficiency can be achieved.

\section{CURRENT CONTROL STRATEGY}

Nowadays, the line-modulated Fixed-Off-Time approach is widely used as a current control method in PFC converters. A simplified scheme of the employed PFC controller is shown in Fig. 13 [17]. This circuit makes $\mathrm{T}_{\mathrm{OFF}}$ as a function of the instantaneous input line ac voltage [16]-[18]. As mentioned before, the proposed converter utilizes two signals to drive the main switches. Therefore, from the main switch gate signal and some logic IC (Monostable and an AND gate) the auxiliary circuit switch gate signal is generated. Any kind of conventional PFC controller can be used with the proposed converter. The simplified extra circuit and the control process are shown in Fig. 14. 


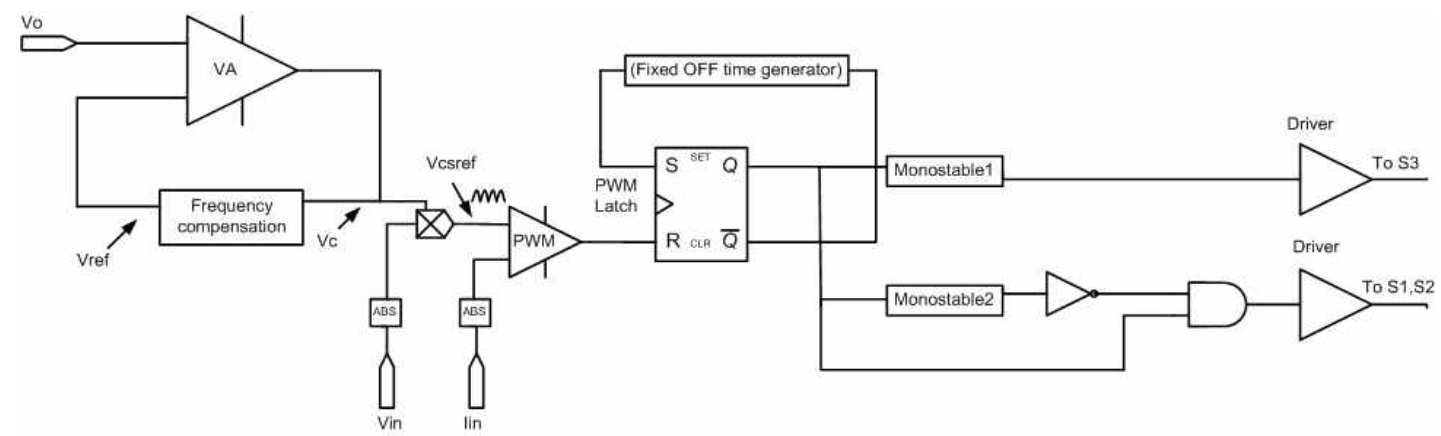

Fig. 14. Auxiliary control circuits block diagram and controller.

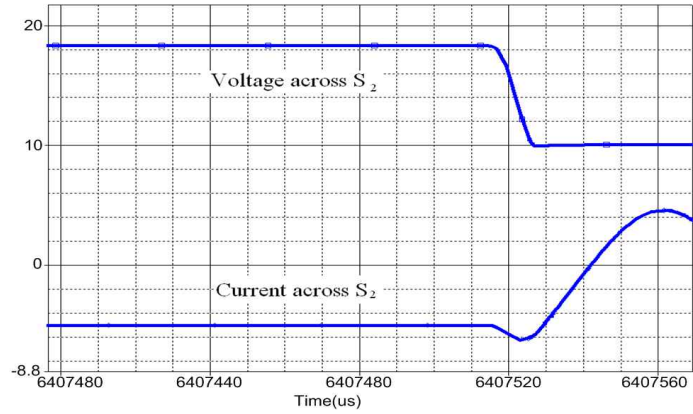

(a)

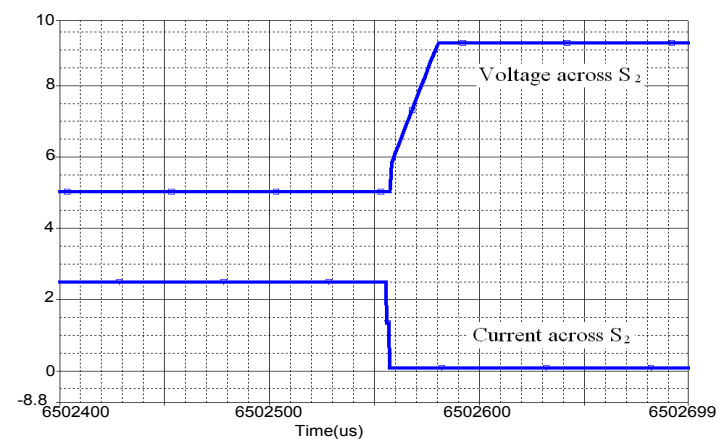

(b)

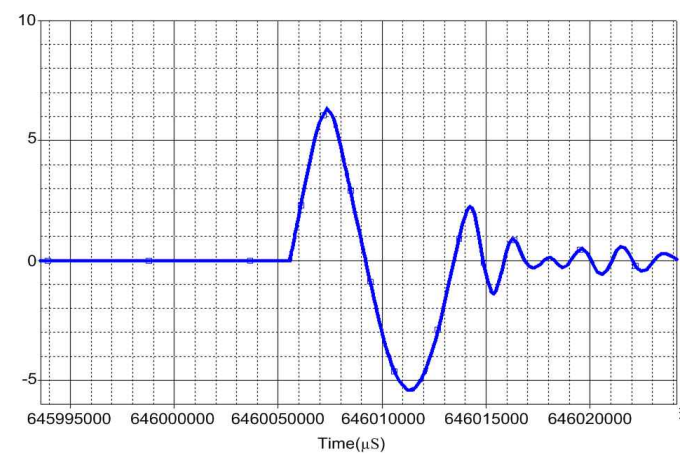

(c)

Fig. 15. Simulation results. a) Voltage and current across main switches S2 (S1 in active mode is short circuit) at turn-on time. b) Voltage and current across main switches S1, S2 at turn-off time. c) Current through Lr.(V: $100 \mathrm{~V} /$ div, I: $1 \mathrm{~A} /$ div, and Time: $5 \mathrm{~ms} /$ div).

\section{DESIGN PRocedure AND EXAMPlE}

The design procedure and an example of the proposed ZVS-PWM bridgeless PFC are described as follows. The specifications of the prototype converter have been tabulated in Table I. The design procedure to obtain the optimum value for $\mathrm{L}$ in Fig. 2 is expressed as follows:

The $\mathrm{K}$ range can be obtained from:

$K_{\text {min }}=\sqrt{2} \times\left(\frac{V_{\text {in }(R M S) \min }}{V_{\text {OUT }}}\right)=95 \sqrt{2} / 400=0.335$
$K_{\max }=\sqrt{2} \times\left(\frac{V_{\text {in }(R M S) \min }}{V_{\text {OUT }}}\right)=265 \sqrt{2} / 400=0.937$

The maximum L current and L can be estimated from:

$$
\begin{aligned}
& T_{\text {OFF }}=\frac{K_{\min }}{f_{\text {sw } \max }}=3.35 \mu \mathrm{s} \\
& \Gamma=\frac{P_{\text {in } 0}}{K_{\text {min }} V_{\text {out }}} \frac{4 \pi K_{r}}{2 \pi-K_{r}\left(4+\pi K_{\min }\right)}=1.54 \\
& L=\frac{V_{\text {OUT }}}{\Gamma} T_{\text {OFF }}=\frac{400}{1.54} * 3.35 * 10^{-6} \\
& =870 \mu H \\
& I_{L p k \max }=\frac{P_{\text {in } 0}}{K_{\min } V_{\text {out }}} \frac{4 \pi\left(1-K_{r} K_{\min }\right)}{2 \pi-K_{r}\left(4+\pi K_{\min }\right)}= \\
& \Gamma \frac{1-K_{r} K_{\min }}{K_{r}}=4 \frac{1-0.2 * 0.335}{0.2}=2.86 \mathrm{~A}
\end{aligned}
$$

\section{A. Calculation of the Resonant Inductor $L_{t}$ :}

The resonant inductor $\mathrm{L}_{\mathrm{r}}$ has to be large enough to limit the boost rectifier's di/dt value, during the turn-off time, so that it is less than $100 \mathrm{~A} / \mathrm{s}$ and not too large. Because, the resonant period $\mathrm{T}_{\mathrm{r}}$ will also be too large, this leads to larger conduction losses in the auxiliary circuit. Therefore, $\mathrm{L}_{\mathrm{r}}$ must be chosen such that the boost diode $\mathrm{D}_{1}$ turns-off when it is at least three times its rated reverse recovery time, as mentioned in [1].

Assuming the rated reverse recovery time of the selected boost diode is equal to $30 \mathrm{~ns}$, the value of $\mathrm{Lr}$ is obtained as follows: 
TABLE I

SPECIFICATIONS Of THE PRototyPe DESIGNEd PFC CONVERTER

\begin{tabular}{|c|c|}
\hline Output power & $250 \mathrm{~W}$ \\
\hline Output voltage $\mathrm{V}_{\mathrm{o}}$ & $400 \mathrm{Vdc}$ \\
\hline Input voltage $\mathrm{V}_{\text {in }}$ & $90-265 \mathrm{Vac}$ \\
\hline Switching frequency & $100 \mathrm{kHz}$ \\
\hline
\end{tabular}

TABLE II

PART List OF THE IMPLEMENTED PROTOTYPE POWER CIRCUIT

\begin{tabular}{|c|c|}
\hline Part & Type \\
\hline $\mathrm{S}_{1}, \mathrm{~S}_{2}, \mathrm{~S}_{3}$ & IRF840 \\
\hline $\mathrm{D}_{1}, \mathrm{D}_{2}$ & HFA08TB60 \\
\hline $\mathrm{D}_{3}, \mathrm{D}_{4}, \mathrm{D}_{5}, \mathrm{D}_{6}, \mathrm{D}_{7}, \mathrm{D}_{8}$ & MUR1540 \\
\hline
\end{tabular}

TABLE III

COMPARISON OF LOSSES IN HARD SWITCHESD BOOST TOPOLOGY AND PROPOSED TOPOLOGY

\begin{tabular}{|c|c|c|}
\hline Type of losses & Hard switched & Proposed topology \\
\hline Main switchs & $12.32 \mathrm{~W}$ & $5 \mathrm{~W}$ \\
\hline auxiliary switch & - & $1.1 \mathrm{~W}$ \\
\hline All diodes & $3.63 \mathrm{~W}$ & $1.9 \mathrm{~W}$ \\
\hline Lboost & $5.5 \mathrm{~W}$ & $5.5 \mathrm{~W}$ \\
\hline Resonant Inductor Lt & - & $0.9 \mathrm{~W}$ \\
\hline Efficiency & $92 \%$ & $94.6 \%$ \\
\hline
\end{tabular}

$L_{r}=\left(3 . t_{r r} \cdot V_{p k} / I_{C 1}\right)=3.30 n s \times 280 / 3.93=6.4 \mu H$

where $\mathrm{V}_{\mathrm{pk}}$ is the peak voltage across $\mathrm{L}_{\mathrm{r}}$, according to:

$$
V_{p k}=V_{o}-V_{C 1(\min )}
$$

\section{B. Calculation of the Resonant Capacitors $\mathrm{Cr}$ and C1,2:}

It can be concluded that $\mathrm{C}_{\mathrm{r}} / \mathrm{C}_{1,2}$ should be chosen to be greater than 1 to reduce both the peak voltage stress across $S_{1}$ and the auxiliary circuit rms current. Although this gives a smaller value for the ZVS turn-on subinterval, an adequate subinterval may still be obtained by choosing $\mathrm{C}_{\mathrm{r}} / \mathrm{C}_{1,2}=3$. Soft switching can be achieved when the following equations are satisfied:

$$
\begin{gathered}
R_{r}=0.21 *\left(V_{o} / I_{\text {in }}\right)=0.21 *(400 / 3.722)=22.57 \\
I_{\text {in }}=I_{\text {in }} p k-I_{r p p} / 2=3.72 \\
C_{r}=L_{r} /\left(R_{r}\right)^{2}=6 \mu H / 509.33=12 n F \\
C_{r} / C_{1,2}=3 \Rightarrow C_{1}=4 n F
\end{gathered}
$$

\section{SimUlation RESUlTS}

To verify the feasibility of the proposed topology, a prototype converter at $100 \mathrm{kHz}$, has been designed and simulated by PSPICE. The employed components have been tabulated in Table II. The voltage across $\mathrm{S}_{2}$ and current through it at the turn-on and turn-off times are shown in Fig. 15. The

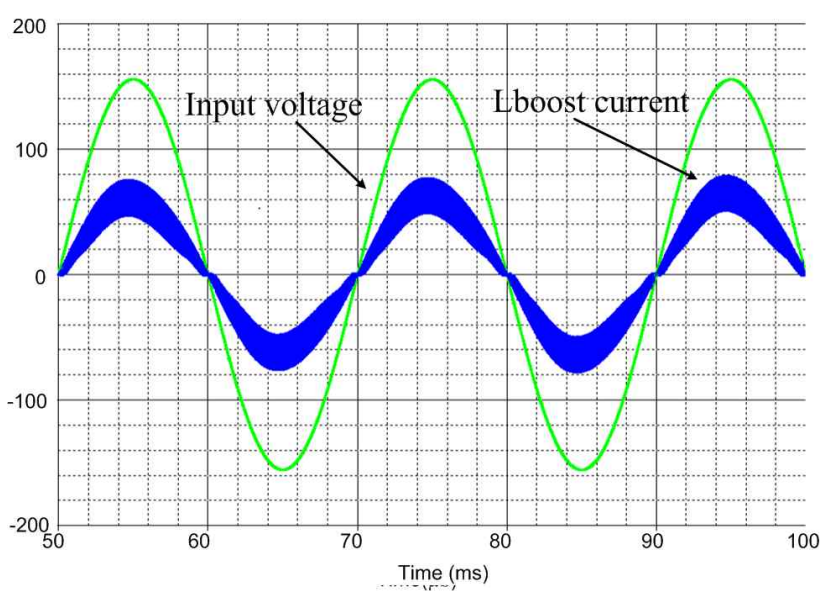

Fig. 16. Converter's input voltage (Vin) and input current (Iin) waveforms.

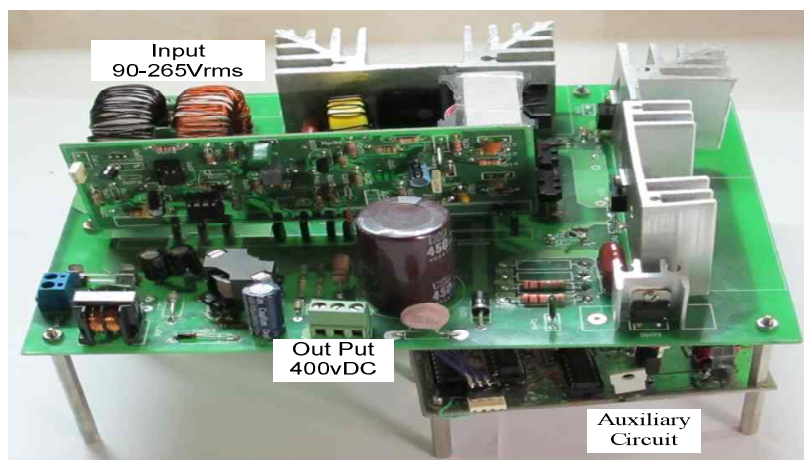

Fig. 17. Prototype of the designed PFC Converter.

waveforms of the input voltage and current of the ZVS-PWM bridgeless rectifier at the rated $250 \mathrm{~W}$ are shown in Fig. 16. It can be seen that the main switches $\left(\mathrm{S}_{1}, \mathrm{~S}_{2}\right)$ turn on with ZVS and turn off at a reduced voltage. Table III gives a comparison of the losses in the conventional hard-switching PWM boost rectifiers and in the proposed ZVS-Bridgeless boost converter. Both converters operate at nominal input voltage $(110 \mathrm{Vac})$ and nominal output power. For the conventional PWM boost rectifier, it can be concluded that the major power dissipations are due to the switching losses.

\section{EXPERIMENTAL RESULTS}

A prototype of the designed and simulated converter in the previous section has been implemented to verify the simulation results and the theoretical analysis. Fig. 17 shows a photograph of the new single-phase ZVS-PWM bridgeless PFC converter. To compare the efficiency, a conventional boost PFC converter with hard switching, a ZVS boost converters using the same auxiliary circuit, a hard switching bridgeless converter and finally the proposed circuit were studies using simple modifications in the same circuit (Fig.18). 


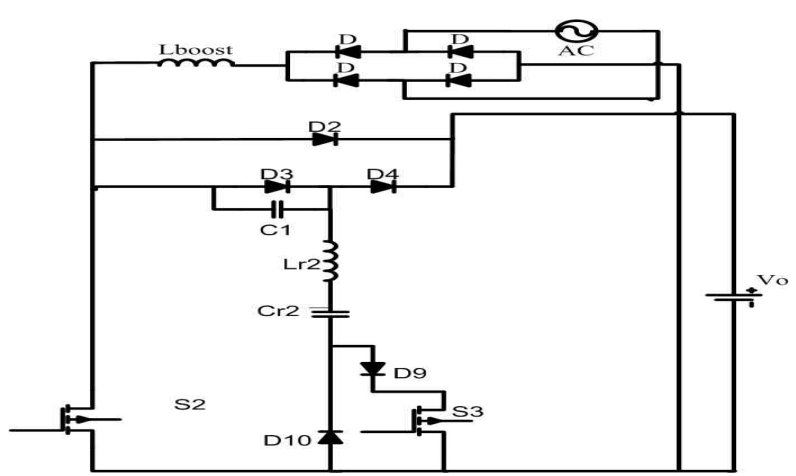

(a)

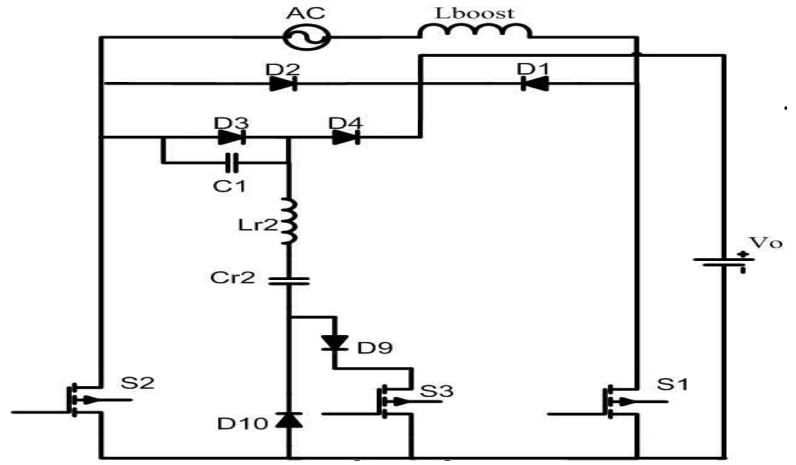

(b)

Fig. 18 . (a) Conventional boost PFC with ZVS in main switch (b) Proposed ZVS bridgeless PFC circuit with one switch in ZVS.

To clear the effect of the auxiliary circuit on the main switches, at first, it has been implemented for one switch, as shown in Fig. 18(b). Fig. 19 shows the waveforms of the voltage across the main switch S2 and the current through it at the turn-on and turn-off times. It is important to adjust the gate drive signals of the main and auxiliary switches exactly. Fig.19(c) shows the gate drive signal of the main and auxiliary switches. The waveforms of the input voltage and current and the input line current harmonics of the ZVS-PWM bridgeless rectifier at the rated $250 \mathrm{~W}$ are shown in Fig. 20.

Based on these waveforms, the current is practically sinusoidal with a low total harmonic distortion (THD) and a high power factor. It can be seen that the experimental results, shown in Fig. 20, are in good agreement with the theoretical analysis and the simulated results which have been illustrated in Fig. 15. Fig. 21 shows the measured efficiencies of the different converters such as the proposed ZVS bridgeless PFC circuit (Fig.2), the ZVS bridgeless PFC circuit with one switch in ZVS (Fig.18 (b)), the conventional boost ZVS converter (Fig.18 (a)), and the hard-switching conventional boost converter.

Depending on the operating conditions, using the proposed converter can improve the efficiency in the range of $3 \%$ to $4.7 \%$.

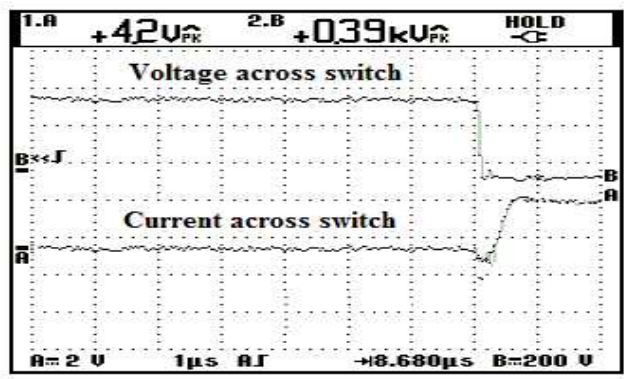

(a)

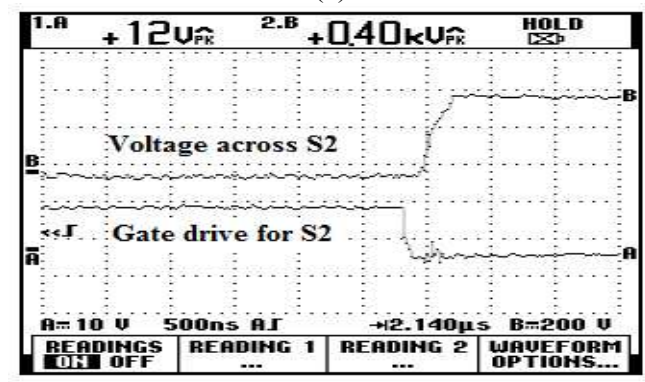

(b)

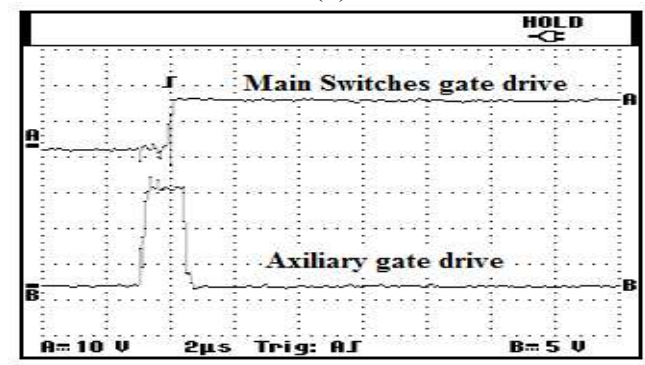

(c)

Fig. 19. Experimental results at $\mathrm{V}=400 \mathrm{~V}, \mathrm{P}=250 \mathrm{~W}$ : (a) main switch S2 at turn-on, (V: $200 \mathrm{~V} / \mathrm{div}, \mathrm{I}: 3 \mathrm{~A} / \mathrm{div}$, and Time: 1us/div) (b) main switch $S_{2}$ at turn-off. (V: $200 \mathrm{~V} /$ div, and Time: $500 \mathrm{~ns} / \mathrm{div})$, (c) main and auxiliary gate drive signal.

\section{CONCLUSIONS}

In this paper, a new ZVS-PWM boost rectifier is presented and realized. Realizing soft switching for all of the stresses is the main advantage of the introduced topology. This converter has a higher efficiency when compared to its conventional PWM hard-switching counterpart, due to the soft switching and the lower conduction losses in the power flow path during rectification. This converter realizes soft switching for both the turn-off and turn on times. The overlap between current and voltage reduces through the main switches during the fall time. Based on the converter analysis, characteristic curves have been obtained and a step-by-step design procedure for the converter has been introduced. Experimental results with a $250 \mathrm{~W}$ prototype at $100 \mathrm{kHz}$, verify the feasibility and advantages of the introduced topology. Based on the given approach, the converter prototype has been designed, and simulation and experimental results have been presented. An efficiency of $94.7 \%$ is achieved which improves the efficiency more than $4.7 \%$, when compared to the hard-switching converter. 


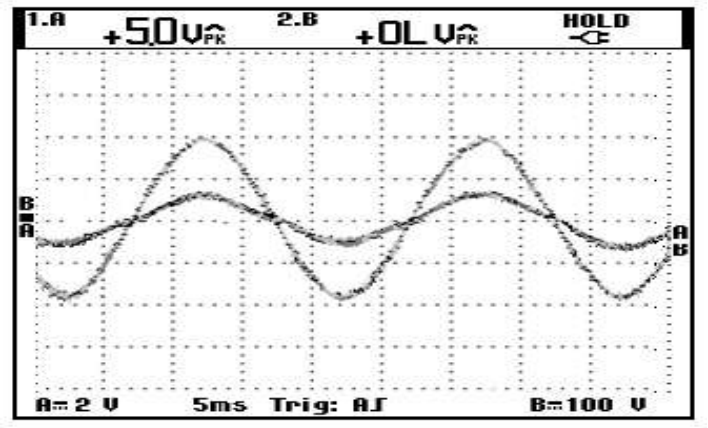

(a)

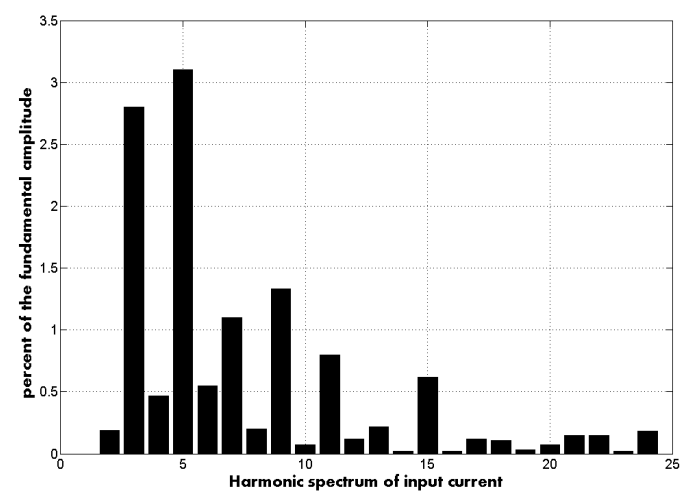

(b)

Fig. 20. (a) Converter's input line voltage and current waveforms (V: $100 \mathrm{~V} / \mathrm{div}, \mathrm{I}: 6 \mathrm{~A} / \mathrm{div}$, and Time: $5 \mathrm{~ms} / \mathrm{div}$ ). (b) Input current harmonics.

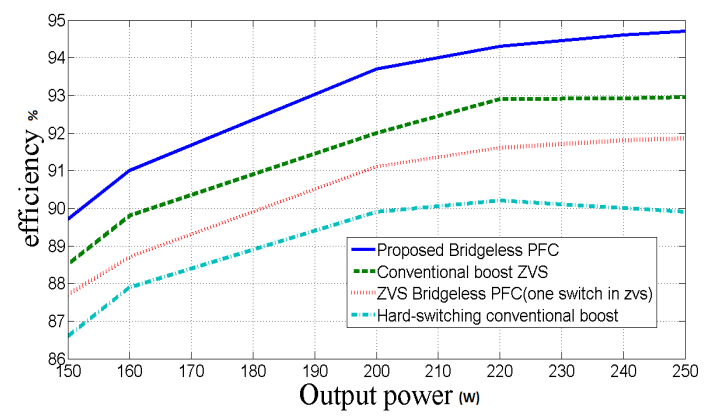

Fig. 21. Experimental efficiencies of the proposed ZVS-PWM Bridgeless PFC and the conventional boost rectifier in 95Vac input voltage.

\section{REFERENCES}

[1] C. M. Wang, "A novel zero-voltage-switching PWM boost rectifier with high power factor and low conduction losses," IEEE Trans. Ind. Electron., Vol. 52, No. 2, pp. 427-435, Apr. 2005.

[2] M. Kazerani, P. D. Ziogas, and G. Joos, "A novel active current wave shaping technique for solid-state input power factor conditioners," IEEE Trans. Ind. Electron., Vol. 38, No. 1, pp. 72-78, Feb. 1991.

[3] A. R. Prasad, P. D. Ziogas, and S. Manias, "An active power correction technique for three-phase diode rectifiers," IEEE Trans. Power Electron., Vol. 6, No. 1, pp. 83-92, Jan. 1991.
[4] H.-L. Do, "Zero-Voltage-Switching Boost Converter Using a Coupled Inductor," Journal of Power Electronics, Vol. 11, No.1, pp. 16-20, Jan 2011.

[5] M. Mahdavi and H. Farzanehfard, "Zero-currenttransition bridgeless PFC without extra voltage and current stress," IEEE Trans. Ind. Electron., Vol. 56, No. 7, pp. 2540-2547, Jul. 2009.

[6] B. Feng and D. Xu, "1-kW PFC converter with compound active-clamping," IEEE Trans. power Electron. Vol. 20, No. 2, pp. 324-330, Mar. 2005.

[7] J. Yungtaek and M. M. Jovanovic, "A bridgeless PFC boost rectifier with optimized magnetic utilization," IEEE Trans. Power Electron., Vol. 24, No. 1, pp. 85-93, Jan. 2009.

[8] H. Y. Tsai, T. H. Hsia, D. Chen "A family of zero-voltagetransition bridgeless power-factor-correction circuits with a zero-current-switching auxiliary switch," IEEE Trans. Ind. Electron., Vol. 58, No. 5, pp. 1848-1855, May 2011.

[9] E. H. Ismail, "Bridgeless SEPIC rectifier with unity power factor and reduced conduction losses," IEEE Trans. Ind. Electron., Vol. 56, No. 4, pp. 1147-1157, Apr. 2009.

[10] J.-H. Kim, D.-Y. Jung, S.-H. Park, C.-Y. Won, Y.-C. Jung, and S.-W. Lee, "High efficiency soft-switching boost converter using a single switch," Journal of Power Electroncs, Vol. 9, No. 6, pp. 929-939, Dec. 2009.

[11] S. K. Kwon, K. F.A.Sayed, "Boost-half bridge single power stage PWM DC-DC converters for PEM-fuel cell stacks," Journal of Power Electronics, Vol. 8, No. 3, pp. 239-247, Jul. 2008.

[12] B. Su, J. Zhang, and Z. Lu "Totem-pole boost bridgeless pfc rectifier with simple zero-current detection and full-range zvs operating at the boundary of $\mathrm{dcm} / \mathrm{ccm}$," IEEE Trans. power. Electron., Vol. 26, No. 2, pp. 427-435, Feb. 2011.

[13] C. A. Canesin and I. Barbi, "A novel single-phase zcs-pwm high-power-factor boost rectifier," IEEE Trans. power. Electron, Vol. 14, No. 4, pp. 629-635. Jul. 1999.

[14] R. Beiranvand, B. Rashidian, M. Zolghadri, and S. M. Alavi, "Design and implement of the PFC Stage of the Ion Implanter's Filament and Arc Power Supplies," ICEE 2009, Vol. 3, pp. 25-32, 2009.

[15] "Application Note AN4121, Design of Power Factor Correction Circuit Using FAN7527B," 2002 Fairchild Semiconductor Corporation.

[16] C. Adriana, AN1792 application note, "Design of fixed-off-time controlled PFC pre-regulator with the L6562," STMicroelectronics, 2003.

[17] C. Adragna, "AN1059 application note design equations of high PF. Flyback converters based on the L6561," STMicroelectronics, 2000.

[18] J. Yang; X. Wu, J. Zhang, and Z. Qian, "Design considerations of a high efficiency ZVS buck AC-DC converter with constant on-time control," IEEE Proc. Telecommunications Energy Conference (INTELEC) 2010, 32nd International, pp.1-5, 2010.

[19] L. Huber, B. T. Irving, and M. M. Jovanovic, "Effect of valley switching and switching-frequency limitation on line-current distortions of DCM/CCM boundary boost PFC converters," IEEE Trans. Power Electron., Vol. 24, No. 2, pp. 339-347, Feb. 2009. 


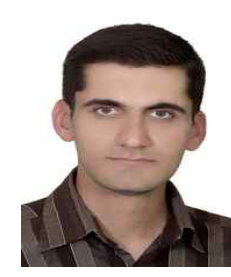

Rasool Haghi was born in Tehran, Iran, in 1984. He received his B.S. in Electrical Engineering from Kashan University, Kashan, Iran, in 2007. He received his M.S. in Electronic Engineering from the Sharif University of Technology, Tehran, Iran, in 2010. His current research interests include switching power supplies and soft-switching techniques in power-factor-correction converters.

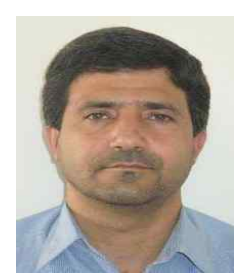

Mohammad Reza Zolghadri received his B.S. and M.S. from the Sharif University of Technology, Tehran, Iran, in 1989 and 1992, respectively, and his $\mathrm{Ph} . \mathrm{D}$. from the Institute National Polytechnique de Grenoble, Grenoble, France, in 1997, all in Electrical Engineering. Since 1997, he has been with the Department of Electrical Engineering, Sharif University of Technology. From 2000 to 2003, he was a Senior Researcher in the Electronics Laboratory of the SAM Electronics Company, Tehran, Iran. From 2003 to 2005, he was a Visiting Professor in the North Carolina A\&T State University, USA. He is the author of more than 70 publications on power electronics and variable speed drives. His current research interests include the application of power electronics in renewable energy systems and hybrid electric vehicles, variable speed drives, and the modeling and control of power electronic converters.

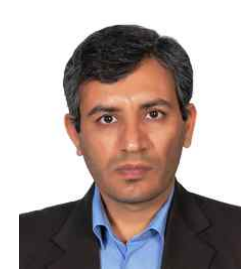

Reza Beiranvand received his M.S. and $\mathrm{Ph} . \mathrm{D}$. in Electrical Engineering from the Sharif University of Technology, Tehran, Iran, in 1999 and 2010, respectively, all in Electronics. From 2010 to 2012, he was a Postdoctoral Research Fellow with the College of Electrical Engineering, Sharif University of Technology, Tehran, Iran. From 1999 to 2007, he was a Senior Engineer at the R\&D Centers of Parselectric and Shahab MFGs, Tehran, Iran, where he was engaged in designing CRTs, liquid crystal displays (LCD) and LED TVs based on Micronas, Philips Semiconductors (now Next eXPerience (NXP) Semiconductors), and ST components. He also worked on high power factor resonant converters for ballasts applications. Since 2012, he has been with the Faculty of Electrical and Computer Engineering, Tarbiat Modares University, Tehran, Iran, where he is currently an Assistant Professor. His current research interests include switching power supplies, the modeling and control of power electronic converters, resonant converters and soft switching, and $\mathrm{PV}$-based renewable energy systems. 